\title{
Analysis on the Development Status of Internet of Things Industry in China
}

\author{
Li Dong \\ Shaanxi Technical College of Finance \& Economics, Xianyang 712000, China
}

Keywords: Internet of Things in China, development, problem

\begin{abstract}
China began as early as the 1990s to pay attention to the study the development of the Internet of Things industry. At present, China is in the middle of the world. The networking industry has formed and possessed materials, technologies and devices. A series of industrial chains, such as components and networks, have reached the Internet of Things to national standards for industrialization. But there are still some deep-seated problems that restrict the development of the Internet of Things to be solved in China.
\end{abstract}

\section{Current Situation of Internet of Things in China}

In recent years, vigorous support of national policies and Industry has developed rapidly. With the continuous efforts of enterprises, China's Internet of Things industry continues to be good. With the good momentum of development, the Internet of Things in China has initially formed a complete system. The industrial system possesses certain technology, industry and application. Basically, the demographic dividend is gradually disappearing and the human cost is rapidly increasing. At present, the application of Internet of Things technology is to solve the problem of human resources.

\section{An Effective Way to Improve Operational Efficiency}

According to the Ministry of Industry and Information Technology, China will consolidate in 2014.The sales revenue of the Internet of Things has reached more than 600 billion yuan. In recent years, China's Internet of Things industry has achieved a comprehensive growth rate. Over 30\% fully reflects its strong development trend. Especially, in the field of intelligent manufacturing industry Internet of Things and Intelligent Transportation Vehicle Networking, Good Market Prospect has high growth whose speed keeps climbing. According to statistical estimation, M2M connection, in China, whose number has exceeded 73 million in 2014, a year-on-year increase 46\%, accounting for $30 \%$ of global M2M connections, continue to maintain holding the World's First Market Position, which in China's M2M Regulation in the Future. The model will continue to expand. It is expected to reach 350 million by 2020, globally whose the proportion will reach $36 \%$. The Internet of Things has become public, in China, which is in terms of application development including the safety, civil Aviation, transportation, environmental monitoring, smart grid, agriculture, industry and other industries, which have been initially applied on a large scale, and some products have already been used. The level of perimeter intrusion prevention system is in the leading position in the world. Intelligent Home, Intelligent Medical Services, etc. for Individual Users. Overall, the development of the Internet of Things industry in China presents itself.

\section{The following characteristics}

First, The Internet of Things Industry is still in its early stage in China. There is no concept introduction period and industrial chain formation stage. Mature Technical Standards and Perfect Technical System, Overall Production. The industry is in the embryonic stage. Previous RFD market expectations. Breakthroughs have been made in the areas of logistics and retailing, but involvement of the industrial chain is too long which the industrial organization is too complex and the transaction whose cost is too high. The problems, such as too high, limited scale of industry, 
whose difficulty in reducing cost and so on, make it difficult for us to do so. The overall market growth is relatively slow. The development of the national Internet of Things industry has great potential. accenture. Research shows that China can further expand the Internet of Things whose influence was directed investment and other similar schemes which is provided support to improve national capacity to absorb Internet of Things technologies. The industry will also generate tremendous added value which taking manufacturing industry as an example which promoted by China's current policies and investment trends in the future. In 15 years, the Internet of Things can create $\$ 196$ billion in manufacturing. The cumulative GDP of RMB. If we further expand the shadow of the Internet of Things. The economic value of China's manufacturing industry will jump to 7360 .

Second, the policy-oriented impact on the development of the Internet of Things in China which is multidimensional policy input to promote the present stage. The strongest driving force for the development of China's Internet of Things industry. If it is to say country, the development of IOT industry belongs to the "market-driven type", domestic which is closer to the "policy-driven". Wenjia since August 2009.Internet of Things has been formalized since Premier Bao proposed "Perception of China". As one of the five emerging strategic industries in the country, it is written into "politics". Government Work Report ", Internet of Things in China by the whole society extreme great attention. After 2015, the Chinese government launched "China" manufacturing 2025 strategy to improve the competitiveness of manufacturing industry. "In Made-in-China 2025 aims to transform China into a manufacturing power, China Improves China's Position in Global Manufacturing Value Chain. By integrating production processes with the Internet, manufacturing industry to become more environmentally friendly, intelligent and quality. In addition, the Chinese Government which is also pushing the "Internet +" strategy to integrate the mobile Internet. With the wide application of technology and intelligent technology, the Internet of Things will become the national promotion of information work. Policy support is expected to continue to increase. Thirdly, under the promotion of government policy, the Internet of Things in China is launched. Exhibitions follow from public management and service markets. To enterprises and industries application of Market and the way to Gradual Development of Individual Family Market is main goal. The concept of Internet of Things was put forward which is urgent to face it. Public management and service areas of demand are indicated by government applications. It will be necessary for Fan project to start the market of animal networking. Then, with the application of public management and service market, it will be solved. Continuous maturity of scheme, it enterprise agglomeration and technology integration. And gradually form a relatively complete industrial chain of the Internet of Things. Thus, it will be able to drive the application market of large enterprises in various industries. Fourth, the industrial system of the Internet of Things is relatively perfect, and the Internet of Thing with sensor industry agglomeration development effect highlights, in many industries. The development platform has been initially formed. Our country has formed covers perception. Manufacturing, Network Manufacturing, Software and Information Processing, Network and Response complete Internet of Things industry with services and other categories. The scale of industry continues to expand has formed around the Bohai Sea, Changsan. The spatial layout of the exhibition shows that the high-end elements are gathered and developed. Internet of Things Platform for Large Enterprises in Enterprise Development has basically taken shape. Small enterprises have joined the ecosphere of large enterprises in the situation of Lida Platform appears. With the application's landing and availability, the gradual accumulation of data mining, the value of the Internet of Things industry begins to appear. Internet of Things and the New is under the Leadership of Information Technology Enterprises in promoting the Cooperative Development of Technology, Innovating Enterprises and Innovating Products.

Fifthly, the development of Internet of Things industry in China is still at the present stage which focus on technological breakthroughs, autonomous MEMS sensor products. industrialization are still the main development of Internet of Things industry. The rapid rise of emerging industries which is as such as the Internet of Things makes biography possible. Sensors are becoming more and more important in the world. In March 2015, Premier Li Keqiang of the State Council proposed 
implementation. The growth rate will be higher than the global average and is expected to reach 2020,more than 300 billion yuan a year.

\section{Problems in the Development of Internet of Things in China}

After several years of development, China's Internet of Things is in technical research development, Standard Development, Industry Cultivation and Industry Application, It has a certain foundation, but there are still some constraints on the Internet of Things. It has deep-seated problems of development needed to be solved

\section{Conclusion}

Infrastructure Lag Supporting the Development of Internet of Things Industry Despite China's rapid economic growth, infrastructure construction is still a long way to go. Because of China's regional economy. The development speed is different, and the development of Internet of Things industry in different regions can not be achieved. Synchronization; Internet of Things infrastructure needs a lot of money, but the different proportion of investment in Internet of Things in different provinces of China, also leads to the lack of synchronization in infrastructure construction of the Internet of Things. In addition, in the process of urbanization, the Internet of Things in rural areas. Infrastructure is backward, coupled with the large population base in China, rural areas. The majority of the population, the popularity and application of the Internet There are great difficulties in the process. So, compared with developed countries, The degree of development and perfection of industrial chain is comparable to that of developed countries such as the United States. There is still a big gap between daggers. In addition, there is industry collaboration. The Internet of Things has a wide range of applications, but barriers between industries, regions and sectors to promote resource sharing and Interactive promotion of system reform and optimization. Because of the different proportion of investment in Internet of Things in different provinces of China, It also leads to the lack of synchronization in infrastructure construction of the Internet of Things. The development of Internet of Things in China is ahead of the country, and private enterprises. The industry has not formed a market-recognized business model for the development of the Internet of Things. Although the scale of individual technology market is considerable, it can not form production. Despite all the Internet of Things industrial parks being uprooted, It's those chains that are engaged in specific technology or application development. The reason lies in the local Internet of Things Industry issued by the local government. To a certain extent, the exhibition mode has become a separate struggle in different parts of the country. It promotes the development of local Internet of Things industry, but at the same time, it has large scale of Internet of Things Development and the Growth Composition of Regional Economy. There are many small and medium-sized enterprises or a small number of large enterprises but there is a lack of them. It is difficult to grasp the development context. Every industry link in the Internet of Things. The degree of development and perfection of industrial chain is comparable to that of developed countries such as the United States. In the industry application, we want to promote the Internet of Things based on sensor technology. This paper is based on the overview of the current situation and potential problems of China's economy. On the basis of the analysis, this paper probes into the problems and points out that China has not yet. The direction of economic development has been discussed preliminarily.

\section{References}

[1] Yu Bin, Wu Zhenyu, China's new economic normal and macro regulation policy orientation reform, 2014, (11).

[2] Li Chungen, China's wealth in the new normal economic development selection of tax policy [J]. tax research, 2015, (04) 
[3] Yangliu, Shen Zhao Zhang, China's financial and tax reform under the new normal emphasis and innovation path]: modern economy, 2015

[4] Zhu Jingkun and Yao Yixin: the construction of a scientific academic management system and operational mechanism in Universities2015.6

[5] Analysis, "Journal of Xuzhou Normal University" [J]. (PHILOSOPHY AND SOCIAL SCIENCES EDITION, 2006 third issue).

[6] Shao Shouxian, Shan Ming Feng: "strategic human resource management in higher education institutions" [J].2016.3 